\title{
Serious games for higher education: a framework for reducing design complexity
}

Citation for published version (APA):

Westera, W., Nadolski, R., Hummel, H., \& Wopereis, I. (2008). Serious games for higher education: a framework for reducing design complexity. Journal of Computer Assisted Learning, 24(5), 420-432.

https://doi.org/10.1111/j.1365-2729.2008.00279.x

DOI:

10.1111/j.1365-2729.2008.00279.x

Document status and date:

Published: 01/10/2008

Document Version:

Peer reviewed version

Document license:

CC BY-NC-ND

Please check the document version of this publication:

- A submitted manuscript is the version of the article upon submission and before peer-review. There can be important differences between the submitted version and the official published version of record. People interested in the research are advised to contact the author for the final version of the publication, or visit the DOI to the publisher's website.

- The final author version and the galley proof are versions of the publication after peer review.

- The final published version features the final layout of the paper including the volume, issue and page numbers.

Link to publication

\section{General rights}

Copyright and moral rights for the publications made accessible in the public portal are retained by the authors and/or other copyright owners and it is a condition of accessing publications that users recognise and abide by the legal requirements associated with these rights.

- Users may download and print one copy of any publication from the public portal for the purpose of private study or research.

- You may not further distribute the material or use it for any profit-making activity or commercial gain

- You may freely distribute the URL identifying the publication in the public portal.

If the publication is distributed under the terms of Article 25fa of the Dutch Copyright Act, indicated by the "Taverne" license above, please follow below link for the End User Agreement:

https://www.ou.nl/taverne-agreement

Take down policy

If you believe that this document breaches copyright please contact us at:

pure-support@ou.nl

providing details and we will investigate your claim.

Downloaded from https://research.ou.nl/ on date: 26 Apr. 2023 


\section{Journal of Computer Assisted Learning}

Serious Games for Higher Education: a Framework for Reducing Design Complexity

\begin{tabular}{|r|l|}
\hline Journal: & Journal of Computer Assisted Learning \\
\hline Manuscript ID: & JCAL-07-043.R1 \\
\hline Manuscript Type: & Article \\
\hline & \\
\hline
\end{tabular}

\section{S ScholaroNE \\ Manuscript Central}




\section{Abstract}

Serious games open up many new opportunities for complex skills learning in higher education. The inherent complexity of such games though, requires large efforts for their development. This paper presents a framework for serious game design, which aims to reduce the design complexity at both conceptual, technical and practical levels. The approach focuses on a relevant subset of serious games, labelled scenario-based games. At the conceptual level it identifies the basic elements that make up the static game configuration; it also describes the game dynamics, i.e. the state changes of the various game components in the course of time. At the technical level it presents a basic system architecture, which comprises various building tools. Various building tools will be explained and illustrated with technical implementations that are part of the Emergo toolkit for scenario-based game development. At the practical level, a set of design principles are presented for controlling and reducing game design complexity. The principles cover the topics of game structure, feedback and game representation, respectively. Practical application of the framework and the associated toolkit is briefly reported and evaluated.

\section{Introduction}

Various authors anticipate the great opportunities of games (and simulations) in education, because of positive effects on learning outcomes (see, e.g. Amory, 2007; De Freitas, 2006; Kiili, 2005; Quinn, 2005). Games have demonstrated to provoke active learner involvement through exploration, experimentation, competition and co-operation. They support learning because of increased visualisation and challenged creativity. They also address the changing competences needed in the information age: self-regulation, information skills, networked cooperation, problem solving strategies and critical thinking. Importantly, games have become widely adopted by new generations of learners, the so-called digital natives, who have grown up immersed in new communication technologies (Prensky, 2006). Although the games industry has grown rapidly over the last decades, the use of games in education is still limited. Despite the great opportunities for synergy, the game industry and education largely act as well-separated sectors driven by their own missions and objectives. Education and games share the idea that participants have to achieve some goal, but game objectives not necessarily match pursued learning objectives. Squire (2002) reports that attitudes to computer and video games are likely to support hyper-competitiveness and warped sexual values rather than wellconsidered learning goals. Garris (2002) and Ma (2007) note that game-based learning often concerns repetition of cyclic content. This provokes persistent re-engagement, which tends to address lower level learning goals rather than higher level goals. Especially in higher education, the mental mode of learning which reflects profundity, reflection, concentration and perseverance, seems to conflict with the mental mode of gaming which is commonly associated with amusement, fun and relaxation. In response to the one-sided entertainment image of games, educators increasingly use the term "serious games" as to indicate that fun and its positive effects on motivation are not the main motives for using games in education (Serious Game Initiative, 2002; Michael et al., 2006).

In higher education, the main objective of applying games is to engage learners in complex problem spaces that mimic real world situations, without importing unwanted constraints and risks of the real world. Learners are challenged to develop relevant knowledge representations and the associated reasoning and problem solving strategies. To this end, learners are supposed to be confronted with ill-defined problems, that often allow multiple solutions and require the application of necessary methodologies or tools and collaboration with fellow learners. An important impediment for such games, though, is the large efforts needed for 
their development. The development of serious higher education games has proven to be complex, time-consuming and costly (Nadolski et al., 2007; Westera et al., 2003). Existing approaches and toolkits for developing leisure games cannot simply be transferred to education because of their very different characteristics. The main objective of this paper is to provide a framework for serious game design, which serves these pedagogical goals and which simultaneously helps reducing the efforts needed for design, development and exploitation. The framework offers a coherent description of the games' basic components and their interrelationships. It also provides a shared vocabulary for game design, and directions for efficient game development. We will first review existing game design frameworks and strategies, and explain their limited applicability for educational game design. Next, we will go into the topic of creating complex and challenging contexts for learning and narrow down our scope to a relevant subset of serious games, labelled as scenario-based games. The framework will be presented in three steps. At the conceptual level we will describe the separate components that make up the game. At the technical level we will present the basic system architecture for scenario-based game development. For reasons of illustration, we will explain its application by referring to the existing Emergo toolkit, which has been based on the conceptual framework (Emergo, 2007; Nadolski et al., 2007). At the practical level, we will present and explain principles for reducing game-design complexity. In conclusion, we will discuss the outcomes of this synthesis.

\section{Literature review}

The domain of games covers a great variety of game genres and modes of play (Gredler, 1992; 2005; Rieber, 2005). Also, very different disciplines are involved like text writing, software development, artificial intelligence, graphics design, video production, marketing, sales and many others. This inherent diversity produces a greatly fragmented domain both from the perspective of design methodology and the underlying theories. The domain of game design is considered semi-formalised, fuzzy and incoherent (Björk et al., 2004) and it eclectically combines various approaches that cannot be fully covered by prescriptive or even descriptive theories. There have been various efforts to produce co-ordinating frameworks for explaining and designing complex games (Salen et al., 2004; Hunicke et al., 2004; Amory, 2007; Björk et al., 2004; Kiili, 2005). But as De Freitas et al. (2006) signal, a dedicated framework for educational games is lacking, which causes a significant impediment for their application. Many frameworks choose a technical perspective by providing authoring environments and other tools for game development (i.e. Java, .Net, mobile learning). Hunicke et al. (2004) have developed the MDA-framework, which attempts to bridge the gap between game design, game criticism and technical game research by iteratively switching between three different levels of abstraction during game design. Unfortunately, the link with education is weak. Salen et al. (2004) have produced a well-elaborated conceptual framework for the analyses of games. Again, little attention is paid to education and learning. De Freitas et al. (2006) review various frameworks that can help teachers evaluate the appropriateness of educational games and simulations for a particulare learning context. The paper presents a 4dimensional framework that extends the existing ones. The framework focuses on evaluation rather than design and thus it does not present strategies or methods for game design. In order to strengthen the link between game design and educational design Burgos et al. (2007) have suggested to develop a framework based on the IMS- Learning Design technology specification. Practical application of the framework is hampered, because it would require complex tooling. Amory (2007) presents a game object model for the development and analysis of computer video games. The model identifies the key concepts of games and it has recently been updated to include educational goals. Due to its general and theoretical level of reasoning, it is of little direct significance for practical, educational game design (Kiili, 2007). 
Because of the insurmountable diversity of games Björk et al. (2004) have suggested to work with game design patterns, which describe well-identified re-occurring problems in game design and offer reusable solutions. The approach neatly addresses the diversity of the domain: it provides a shared vocabulary of game elements, allows structured comparison between games and supports component-based tooling. Over 200 game design patterns have been identified. However, the framework provides only very little support for the integration of patterns into an appropriate game. Dickey's (2005) research suggests that various game design strategies for achieving player engagement (like narrative, viewpoint, setting and roles) can be applied for the design of engaging learning environments. Kiili (2007) focuses on games for experiential learning and looks into the conditions that contribute to achieve experiential flow. Although the research of Kiili explicitly links educational theory with game design, it sincerely reports not to be able to address or improve game design. Various approaches have been developed to cover specific types of games, for instance class room games or massive multi-user online games (Steinkühler, 2004). These approaches have only little significance for serious game design. For audiovisual design and narrative, various frameworks are available, but these are not necessarily tuned to audiovisuals in serious game design (Koumi, 2006; Westera, 1999). Altogether, quite some valuable frameworks are available that enhance our understanding of games. But they generally provide only little design directions, often lack a pedagogical perspective and fail to suggest how to deal with game complexity.

\section{Method}

Although complexity is a keyword for serious games, education does not require complexity per se: it demands controlled complexity in support of effective learning. Theoretically, there are two opposite ways for generating complexity. First, complex structures can emerge from the self-organised nature of a collection of interacting agents. Here, examples would be plants, ant-hills, climate, ecosystems, etcetera. Such systems are characterised by large numbers of agents interacting according to simple generic rules. As is the case in common multiplayer games like football or baseball very complex situations can emerge from the simple rules of play that regulate the behaviours of the participants (agents). Each run of such game will be greatly different and unpredictable, which indeed makes these games quite exciting. Exactly such uncertainty of the system is a direct threat for education, because it is unclear whether the emerging events match the required learning goals. Secondly, complexity can be created by design. The great advantage of such an approach would be that the complexity is largely controlled, as is the case in many human artefacts like micro-circuit design, the production of medicines or the construction of aeroplanes. Because education is about well-tailored learning rather than carefree playing, education is prompted to create complexity by design. Even when the growing interest in Web 2.0 and social networking increasingly demonstrate the possibilities of self-organised structures, the behavioural complexity of higher order competences cannot be covered in all extent by simple generic rules. It is very unlikely that agent-based approaches combined with simple behavioural rules - as displayed in football or baseball - produce learning environments that are sufficiently tuned to support the effective acquisition of predetermined academic learning objectives. A agent-based game design would require a large set of behavioural rules in order to stay tuned to its objectives: it thus would drift toward a complexity by design approach. Although emergent complexity can be useful to a certain extent - as is the case with random noise -, serious games cannot do without a pre-structured complexity that is based on a narrative or scenario, covering the dynamics of the game. Indeed, Murray (1997) and Crawford (2005) stress the importance of narrative content in computer-based learning. Lindley (2005) also stresses the importance of pre-designed narrative content, because it allows structured 
experiences in time, but still enables the players to exert their personal preferences. Such scenarios allow education to emphasise functional complexity and to reduce types of complexity that are irrelevant to learning.

So, the starting point of our approach is designed complexity rather than emergent complexity. It thus identifies a subset of serious games which can be labelled scenario-based serious games or case-based serious games (Galarneau, 2005; Nadolski et al., 2007). Here, predefined rules are used rather than individual agents to arrange program flow, required achievements and access to new features. There are many examples of such games (occasionally labelled virtual practicals) that conform to the demands of higher education (Nadolski et al., 2007). They all share the tendency to designed complexity and the associated great development efforts. Before elaborating our approach we summarize the main characteristics of the subset of pursued scenario-based serious games.

- The environment

Learners are exposed to a challenging context for learning, that mimics real world situations, displays ambiguity and conflicting information and offers large degrees of freedom.

- The learning activities

Learning activities involve complex decision making, problem solving strategies, intelligent reasoning and other higher order skills. They are based on professional or academic role adoption and modelled after expert behaviour. Learners are in charge to deal with complex problems according to professional or scientific standards.

- Multi-user

Complex real world problems are likely to involve several participants. The games should thus allow multi-user scenarios. Single user solutions are possible, when some of the actor roles are covered by the computer.

- Methodology

Expert behaviour is framed by one or more methodologies or strategies, which can be used to counter trial and error behaviours, to control complexity and to act as a reference for generating relevant feedback during the game.

The proposed game design framework applies essentially to the subset of scenario-based games. It combines three different levels of description. At the conceptual level, a game is considered a system: a set of interrelated or interacting elements that constitutes a complex aggregate (Littlejohn, 1983). Designing a game involves specification of the relevant elements, while taking into account the two fundamental dimensions of space and time. The space dimension covers the static configuration of the (virtual) game locations, including the associated objects, attributes and relationships. Its development over time covers the dynamics of the game, viz. the evolution and the state changes of the game elements. At the technical level, the framework describes the basic system architecture of scenario-based game development: it characterises the required tooling system and its separate tools to deal with the development of game locations, objects, actor roles and game scenarios. At the practical level the framework provides principles for reducing design complexity. These principles refer to the way the game is structured, to the feedback that is offered to learners and to the multimedia representation of the game environment, respectively. A glossary of relevant terms that are used in the framework, is available at the end of this paper. 


\section{Framework description part 1: conceptual level}

We will start with the static game configuration. The educational game environment is assumed to comprise four distinct sub-systems: the world of game play, the learner world, the teacher world, the game management world (Figure 1).

\section{$<<$ FIGURE 1 ABOUT HERE $>>>$}

In the world of game play learners carry out their learning tasks by accessing the locations of the game and the game objects. The learner world is a separate environment that extends and complements the context of the game play. It contains the assignments and the players, which may be individuals as well as groups. It allows players to cross the so-called magic circle (Huizinga, 1938), which is the social "contract" agreed upon by the players, that defines the physical and temporal boundaries of the game. Likewise, the tutor world provides a metachannel, transcending the game play, which allows tutors to assess progress, provide feedback and make interventions. In pervasive games the magic circle is blurred because game play and ordinary life become greatly intertwined (Montola, 2005). This blurring may also occur in education when the learning is greatly connected with ordinary life, as is the case in various modes of informal learning, apprenticeship learning and workplace learning (Westera, 2000). The fourth sub-system is the world of game management: here, the different game runs are arranged and co-ordinated, users are registered and new game scenarios are added. Below, we will focus on the world of game play. Indeed, as Kiili (2005) notices: game play is the most critical feature of game design.

Objects are the building blocks of the game environment. When applying a spatial metaphor, the principal objects of the game environment are the game's locations. The game world may comprise different locations which can be visited and which may provide access to different tools, resources or fellow-players. Locations may also cover abstract entities like pages, table cells or other representations that define a particular environment for specific actions.

Navigation to the various locations may be regulated by admission and prohibition rules. For instance, one might state that location A can only be accessed from location B or location C, being its neighbour locations, but not from location D. Also, learner performance conditions may be used to regulate location access ( $\mathrm{A}$ is accessible only if learner $\mathrm{X}$ has visited location $\mathrm{Y}$, or has completed task Z, etc.). All too often games display many scenery objects that have aesthetic or atmospheric value as such, but which are irrelevant to the problem solving process. Unless such extensions are necessary to effect a realistic, cluttered context, they are likely to distract the learning rather than support it (Koumi, 2006). Locations are assumed to contain various types of objects, be it tools like machines or telephones, or knowledge resources like videos or documents. Naturally, the objects should have some relevance for the learner's assignment, that is, they should display relevant features or allow appropriate interaction. Locations may also contain subjects (which formally are a subclass of objects). These are fellow-participants who make up the social dimension of the game by enabling communication, co-operation, opposition or competition.

The world of game play need not be a closed, self-contained environment. In addition to the predefined locations and objects, players may also extend the game universe by utilising external channels and objects in order to optimise their performances. Some of these external channels can be incorporated in the game logic. For instance, the development of share prices or topical weather reports can easily be fed into the scenario engine to enhance the dynamics and the authenticity of the game. External channels also allow the incorporation of expert consultation, external forums, external tools, external archives, which aren't necessarily linked with the game logic. 
Next we will go into the dynamics of the game. The dynamics of the game include the state changes of the various game components. According to Björk et al. (2004) playing a game is just making changes in game states. The overall game state is the aggregate of the states of all components of the game, including the progressive states of learners. State changes is also referred to as events. In order to make events take place, any status information has to be tracked and stored for all objects and players of the game. State changes are triggered when certain conditions within the game are met. The collection of triggers and the underlying rules acting on the game world and its users is referred to as the game logic: it comprises the constitutive and operational rules of the game (Salen et al., 2004). Naturally, many state changes will be triggered by the players' actions, for instance moving an object, selecting a document or completing a multiple choice question, etcetera. But state changes may also occur by internal triggers that regulate the autonomous evolution of an object's state attributes over time. Attributes may concern any object quality: position, angle, speed, colour, size, age, visibility, etcetera. Computational models may be used for incorporating gravity, kinematics, the daily cycle of light and dark, for birth and death of objects or, in general, population dynamics and system evolution. In many games complexity and unpredictability is created by random triggers, often in conjunction with some probability distribution function. For critical events, however, users may find it difficult to anticipate these unexpected, arbitrary changes. Indeed, from film theory it is known that viewers should be prepared to radical changes of state by providing explicit of implicit clues in order to avoid frustration or annoyance (Kuomi, 2006). For the larger part, state changes in scenario-based games are controlled by predefined rules, scripted as Boolean expressions. Defining such Booleans may be very laborious and complex, because numerous rules are needed and each rule may contain any state parameter of any object. This is an important impediment for the development of scenario-based games. An essential condition for the feasibility of scenario-based games is the restriction of the overall number of system states. Practically this means that the game scenario aims to reduce the option space for learners, that is: at any location or point in time learners may choose only from a limited number of alternative actions. The basic lay-out of such focused scenario reflects a decision tree, which incorporates all possible routes learners can take (cf. Figure 2).

$<<<$ FIGURE 2 ABOUT HERE $\gg>>$

Note that the basic pattern of Figure 2 only depicts the principle of restricted option space. It is about decisions, not about content selection or content testing, and therefore it should not be mistaken for a simple collection of successive multiple choice questions. Likewise, the structure does not constrain the games to closed scenarios. For instance, when at a certain point in time learners are asked to consult a subject matter specialist of their choice or to produce an original text, musical score or videoclip, the outcome is uncertain, but still it is one option.

\section{Framework description part 2: technical level}

At the technical level, a tooling system would be needed, which allows game development and implementation. Essential features of such tooling system follow directly from the conceptual framework. Its basic layout is displayed in Figure 3.

$<<<$ Figure 3 ABOUT HERE $>>>$ 
From the perspective of game play, the game-development architecture comprises four types of tools. First a location builder is necessary to define the game locations. Second, an object builder is needed to specify objects and the associated objects' attributes. Various types of objects will be needed to build a sensible game. Therefore, the object builder will comprise a series of different building tools. Third, the role builder allows to specify different player roles, associated with different tasks and different powers. Fourth, a scenario builder helps specifying the logical conditions that make up the game play scenario. Each object or each class of objects should exhibit a range of well-defined state attributes that can be addressed and influenced by the scenario builder. Naturally, during game play the execution of the game logic requires monitoring and logging of all state data of the system. These include the states of locations, the states of objects and the states of the players.

Technically, the architecture of Figure 3 may be implemented with any programming platform. To demonstrate the power of the approach we refer to the Emergo methodology and toolkit (Nadolski et al, 2007), which have been developed for the efficient creation of complex scenario-based games. The Emergo project has identified a number of essential objects and interaction modes for scenario-based game play. The Emergo toolkit contains various authoring and scripting tools to define and assemble scenario-based games. It uses a layered architecture according to the model-view-controller model and it applies web services for the interfaces with external systems. It is fully web-based and uses the J2EE/Java development platform. The toolkit has been made available under a General Public License (Emergo, 2007). Below we will briefly describe a relevant subset of the Emergo tools.

\section{The location builder}

This building tool is used for the definition of locations that are relevant to the game scenario. Locations are simply represented on the screen by a background graphic or photograph and a label. By defining a location rule (using the scenario builder) the background graphic may be switched. This way the location may have different appearances at different conditions (daylight, night time, weather appearance, etcetera). An important state parameter of a location is 'visited by player' (yes/no). Such parameters are logged and are available for defining Booleans with the scenario builder. The list of locations is fed into the navigation controls.

\section{The task builder}

The task object builder is used to specify learning tasks. It simply comprises a text field for the description of the task assignment and some attributes to indicate whether the task is optional or not, whether it requires previous tasks to be completed first, and what learner output is required for the task to be completed. The attributes 'accessed/not-accessed' and 'completed/'not-completed' indicate important state values for tracking learner progress and providing feedback.

\section{The email builder}

This tools allows developers to generate pseudo email messages that will become available for the players when certain conditions are met. The email messages may contain clues within the scenario that induce the learners to undertake actions or to adapt their strategies. The relevant state values of an email message would be 'accessed by player X' and 'not-accessed by player X'. 


\section{The selection builder}

This tool is used to offer learners the opportunity to explicitly select relevant options. This includes single answer questions (a deliberate decision) and multiple answer questions (filtering of a relevant subset of options). Also the ranking of items can be included. Naturally, the choices are logged and applied in the game logic to generate new events or feedback.

\section{The interview builder}

The interview builder enables the game developer to create a predefined interview. It applies lists of questions that are linked to video streams of the interviewee (see Figure 4). This way non-playing characters within the game play can be consulted (i.e. a subject matter expert) or can be assessed (i.e. diagnosing a patient).

\section{$<<<$ FIGURE 4 ABOUT HERE $>>>$}

The interview object's state parameters include 'question asked' (yes/no) and 'video played' (yes/no). Evaluation of the interview may be carried out by checking what questions have been asked and what questions have been skipped. Alternatively, the learner may be asked to make a summary of the interview, by using the report tool which is also part of the Emergo toolkit.

\section{The object evolution builder}

This tools allow the game developers to define autonomous changes of an object's abstract states. This is achieved by identifying relevant properties and associated state values (for instance room temperature: 38 degrees centigrade, or colour: blue). The object's state changes may be triggered by time (evolution, life cycle), by player interactions or by other changing conditions of the game play world.

\section{The role builder}

The role builder is a management tool which allows the specification of multi-user scenarios by assigning different roles and powers to each user.

\section{The scenario builder}

The scenario builder is the intelligent core of the game development system. It is connected to all objects and their state values and it is largely used to define the rules of the game dynamics. The general form of a rule reads:

$$
\text { IF stateparameter }(\mathrm{X})=\mathrm{p} \text { THEN stateparameter }(\mathrm{Y})=\mathrm{q}
$$

The state parameters may concern any objects, subjects or locations within the game environment. The antecedent of the rule may be extended to any Boolean combination of state parameters. Likewise, the consequence of the rule (the event) may be extended to describe multiple state changes. The state changes cover various operations, which include showing and hiding of objects, generating feedback, generating an email, setting an internal game parameter and locking or unlocking of locations. The state parameters reflect the key elements 
of the game dynamics; Table 1 summarises the general state attributes of the various game components with regard to a each player.

\section{$<<<$ TABLE 1 ABOUT HERE $>>>$}

It should be noted that the Emergo toolkit contains various additional building tools that are not explained in this paper, for instance tools for creating tests, agendas, portfolio's and reports and tools for addressing learning resources. Moreover, the modular architecture of the toolkit allows extension with additional game building tools. In accordance with the design framework an ADDIE-based methodology for scenario-based serious games has been described by (Nadolski et al., 2007). The methodology offers important considerations for designing scenario-based games. But still, the natural tendency of toolkits and methodologies is to enable a wide range of game applications differing in size, purpose and complexity, and therefore game designers are likely to stumble into the pitfall of unmanageable complexity, turning the toolkit's strengths into a fundamental weakness. Since the states of many game objects will be greatly interlinked with the learners' states, a combinatory explosion of required specifications may occur. In order to counteract this risk, methodologies for scenario-based game design need to be extended with explicit guidelines how to deal with complexity.

\section{Framework description part 3: practical level}

On top of the conceptual framework, the development system architecture and the design methodology, a set of design principles are needed for controlling and reducing game design complexity. Any scenario-based game-design methodology should incorporate such principles to support the affordable development of complex serious games. The principles cover the topics of game structure, feedback and game representation, respectively. We will explain these below.

\section{Reducing structural design complexity}

From Figure 2 it can be observed that the complexity of the decision tree increases rapidly with increased depth. Although such complexity matches the starting points of educational games, it would take a lot of effort to elaborate and specify all decision nodes. Four approaches are proposed that reduce structural design efforts.

- Option width rather than option depth:

In conflict with the sequential nature of scenarios or narratives, the complexity of the decision tree is best reduced by choosing small values for the depth. For instance, swapping the values of depth $(n=4)$ and width $(m=2)$ of Figure 2 reduces the number of nodes from 63 to 29 (cf. Figure 5). Paradoxically, learners may experience larger complexity in this alternative structure, because experienced complexity is determined by instantaneous option space (width) rather than sequential option space (depth). For large tree depth $m$, halving of $m$ reduces the tree complexity of order $n^{m}$ approximately a factor $\bigvee_{\mathrm{n}}$.

\section{$<<$ FIGURE 5 ABOUT HERE $>>>$}

- Shallow distracters

Often many branches of the decision tree can be omitted. Shallow distracters can be applied to create the impression of option spaces. These can be dummy options that suggest a sensible alternative, but when activated a message is displayed that the 
option is not available. Second, a dead-end distracter is used involving some tasks or activities, but at certain conditions (e.g. time past or completion) these are terminated and the learners return to the original decision node to reconsider their behaviours. Third, a distracter can also act as a single sidestep of the main road; completion of the distracter would redirect the learners back to the preferential scenario, with or without any corrective comments. Eventually, learners will find out, either by inhibition rules or by corrective feedback that they have spend valuable time at irrelevant activities.

- Closures

Game closures are certain game states that correspond with the completion of one or more achievements and that trigger access to a new episode, activity or level of the game. Closures reduce design complexity since they mark the start of a new tree. They often come with methodologies, which usually comprise a number of subsequent phases, as is the case in scientific research. Closures are removed when learners have met certain criteria in their game play. Basically, three different types of criteria can be distinguished: activity-based, route-based and performance-based.

- Parallel task execution

Complex tasks often require the parallel or iterative execution of activities. Many strict methodologies are sequential in kind, but cannot be applied unthinkingly to practice.

Parallel task execution is difficult to describe in a single decision tree. As the learner is supposed to occupy only one single position in the tree, various cross referential bypasses would be necessary to enable traffic from one branch of the tree to the other. Ultimately, all nodes might be connected to each other, which would produce very complex structures and routes. Instead, it is important to identify the separate, underlying activity classes and model these as separate decision trees with there own structures and there own state logging. Thus, multitasking conditions are created which allow learners to temporarily switch from one activity tree to a second activity tree, and to return after a while to the recorded position in the initial tree.

\section{Reducing feedback design complexity}

For educators it is often hard to resist the tendency of tracking and evaluating any learner action, so that they are able to provide detailed feedback. Commenting on any single step in the game, however, would require an almost indefinite number of extended rule-sets to generate the appropriate feedback. Two separate approaches are proposed to reduce the efforts of feedback design:

- Strategic performance feedback

Rather than commenting on a micro level, feedback should be generated at high aggregation levels. Learners wouldn't be too interested in receiving direct feedback on every single action or decision, but instead they want to be informed about their overall progress, about their approach, how well they perform and how they can improve it. This nicely matches the strategic nature of scenario-based problem cases. The associated assessment model should be restricted to only a few aggregate dimensions, for instance the quality of performance, the speed of performance and performance style. Quality of performance presupposes a rating method that is based on start or completion of necessary activities. Speed of performance can be easily related to (nett) session time. Performance style measurement would incorporate some of the learners' routing behaviours, the degree of parallel processing and probably the learners' responses to natural feedback.

- Including peer feedback As Amory (2007) put it: educational games should support authentic learning 
activities that are designed as narrative social spaces. The multi-user dimension opens up great opportunities for the arrangement or emergence of peer feedback. Several authors report that giving and receiving peer feedback has positive effects on motivation, reflection, self-esteem and commitment (Anderson, 2000; Fantuzzo, 1989) and produces higher learning outcomes (Fantuzzo, 1989; Rosmalen, 2005; Wong, 2003). First, peer feedback may be part of the game scenario, as is the case in many management games where company teams compete against each other. Secondly, peer feedback can also be arranged outside the game scenario, transcending the game play world by stimulating the community of players to comment on their game performances. As Barab et al. (2005) point out games are promising environments for experiential learning but they tend to focus on action rather than reflection, which greatly conflicts with experiential learning theory of Dewey (1938) en Kolb (1984). Since peer feedback establishes reflection as a distinct activity it may improve the intrinsic quality of learning.

\section{Reducing representation design complexity}

Many entertainment games owe their successes to outstanding graphic sceneries, character animations and sound. These high representation standards put high pressures on educational game developers to attain the same level of sophistication and complexity. To this end it is important to distinguish between authenticity of content and authenticity of representation. Naturally both are relevant, but there is some evidence that authenticity of representation is less critical than authenticity of content. In serious games the content itself contributes substantially to tension and involvement. In addition, the media equation theory of Reeves et al. (1996) claims that only very little representational or technological efforts are necessary to provoke true inter-personal responses. An example would be original games like Pac-Man which simple graphical interfaces arouse great tension and excitement of players, even when the monsters hardly look like monsters. Apparently, what counts is not realism or authenticity but credibility. Without trivialising the scenery of the game-play world, it is important to note that a functional analysis of the game contents and the game scenario is necessary to decide on representation topics. The proposed framework provides a useful vocabulary for recognising the functional importance of game components. Naturally, the representational efforts in game components should properly align with their functional importance.

\section{Discussion}

In this paper a conceptual framework for scenario-based game design has been proposed. The framework has been applied to develop a system architecture and the associated tools for efficient scenario-based game development. A corresponding design methodology for scenario-based games has been explained elsewhere (Nadolski et al., 2007). An important goal of the approach is to reduce the efforts needed for design, development and exploitation. It is a response to the inherent diversity and complexity of game design which calls for applicable guidelines and methods for the improvement of game design. The foundation of the framework is theoretical in kind, but its development was strongly linked with the practice of educational game development, in particular with the development of the EMERGO toolkit and methodology. So far, the EMERGO methodology and toolkit has been used to develop seven separate scenario-based games in various domains. These include environmental sciences, psychology and education, as part of the educational programmes of the Radboud University, Utrecht University, Maastricht University and the Open university of the Netherlands. Additional games are considered for management and law. The games involve complex problem scenarios which address higher order (academic and professional) skills. 
The size of the games is up to 60 hours of study load, while production efforts including production of video and graphics design, have been reported up to 1500 hours. This yields a production ratio of 1:25, which is much lower than common standards for computer-based learning programs (cf. ranging from 1:100 towards 1:600; Alessi et al., 2001). The approach supports the instructional design process well. A brief evaluation amongst 8 teachers showed that they were well able to use the authoring tools without any support. It must be added that almost all game development took place within the context of our distance learning institution, which inevitably introduces some bias of teachers in favour of e-learning, rich media and gaming. The teachers appreciated its flexibility and the large range of learning scenarios it caters for. It must be said that in the case of sophisticated scenarios, additional support remains essential. Especially, the design of conversations and game logic are likely to become too complex for teachers, as was the case in the domain of environmental policy. To this end, it can be remarked that once a scenario is finalised, its structure becomes available for the community of teachers to serve as a template for reuse with different content. With respect to produced games themselves, teachers valued their usefulness for efficiently preparing students for handling real-life problem situations. Preliminary tests with students indicate high appreciations, especially with regard to the game structure, the alignment with prior skills and, interestingly, the credibility of the game representation. The latter seems to conform to the principle that authentic representation is less critical than content credibility, because simple graphics dominated the games' user interfaces. Additional research will be necessary to establish the framework's effectiveness and to evaluate the learning outcomes in connection with particular scenario types. This would also provide the opportunity to link the work with different strategies, descriptions and tools in order to get closer to the ideal of a shared serious gaming paradigm.

\section{References}

Alessi, S.M. \& Trollip, S.R. (2001) Multimedia for learning: Methods and development. Allyn and Bacon, Needham, MA.

Armory, A. (2007) Game Object Model Version II: a Theoretical Framework for Educational Game Development. Educational Technology Research and Development 55, 51-77.

Anderson, A., Cheyne, W., Foot, H., Howe, C., Low, J. \& Tolmie, A. (2000) Computer Support for Peer-Based Methodology Tutorials. Journal of Computer Assisted Learning 16, 41-53.

Barab, S.A., Thomas, M.K., Dodge, T., Carteaux, B. \& Tuzun, H. (2005) Making learning fun: Quest Atlantis, a Game without Guns. Educational Technology Research and Development 53(1), 86-107.

Björk, S. \& Holopainen, J. (2005) Patterns in Game Design. Charles River Media, Hingham MA.

Burgos, D., Tattersall, C. \& Koper, R. (2007) Re-purposing Existing Generic Games for ELearning. Computers in Human Behavior 23(6), 2656-2667.

Crawford, C. (2005) Chris Crawford on Interactive Storytelling. New Riders Publishing, Indianopolis IN. 
De Freitas, S. (2006) Learning in immersive worlds. Bristol Joint Information Systems Committee. Available from here (last accessed December 15, 2007).

De Freitas, S., \& Oliver, M. (2006). How can exploratory learning with games and simulations within the curriculum be most effectively evaluated? Computers \& Education, 46, 249-264.

Dewey, J. (1938) Experience and Education. The Macmillan Publishing Company, New York.

Dickey, M. D. (2005). Engaging by design: How engagement strategies in popular computer and video games can inform instructional design. Educational Technology, Research and Development, 53(2), 67-83.

Emergo (2007) Emergo project website. Available from here (last accessed December 15, 2007).

Fantuzzo, J.W., Riggio, R.E., Connelly, S. \& Dimeff, L. A. (1989) Effects of Reciprocal Peer Tutoring on Academic Achievement and Psychological Adjustment: a Component Analysis. Journal of Educational Psychology 81, 173-177.

Galarneau, L. (2005) Authentic Learning Experiences through Play: Games, Simulations and the Construction of Knowledge. Digital Games Research Association (DiGRA), Vancouver. Available from here (last accessed December 15, 2007).

Garris, R., Ahlers, R., \& Driskell, J.E. (2002) Games, Motivation and Learning. Simulation and Gaming. An Interdisciplinary Journal of Theory, Practice and Research 33(4), 43-56.

Gredler, M.E. (1992). Designing and evaluating games and simulations. Kogan Page, London.

Gredler, M.E. (2004). Games and simulations and their relationships to learning. In, Handbook of research on educational communications and technology 2nd ed. (Jonassen D.H., ed.), pp. 571-581). Lawrence Erlbaum Associates, Mahwah, NJ.

Huizinga, J. (1938/1955) Homo Ludens: A Study of the Play Element in Culture. Beacon Press, Boston.

Hunicke, R., LeBlanc, M. \& Zubek, R. (2004) MDA: A Formal Approach to Game Design and Game Research. Game Design and Tuning Workshop at the Game Developers Conference, San Jose. Available from here (last accessed December 15).

Kiili, K. (2005) Digital Game-Based Learning: Towards an Experiential Gaming Model. The Internet and Higher Education 8-1, 13-24.

Kiili, K. (2007) Foundation for Problem-Based Gaming. British Journal of Educational Technology 38(3), 394-404. 
Kolb, D. (1984) Experiential Learning: Experience as the Source of Learning and Development. : Prentice Hall, Englewood Cliffs, NJ.

Koumi, J. (2006) Designing Video and Multimedia for Open and Flexible Learning. Routledge, New York.

Lindley, C.A. (2005) Story and Narrative Structures in Computer Games. In Developing Interactive Narrative Content, Sagas/Sagasnet Reader (Bushoff, B., ed.). High Text, Munich.

Littlejohn, S.W. (1983) Theories of Human Communication (2nd ed.). Wadsworth Publishing Company, Belmont, CA.

Ma, Y., Williams, D., Prejean, L. \& Richard, C. (2007) A Research Agenda for Developing and Implementing Educational Computer Games. British Journal of Educational Technology 38(3), 513-518.

Michael, D. and Chen, S. (2006). Serious games: games that educate, train and inform. Thomson Course Technology, Boston, MA.

Montola, M. (2005) Exploring the Edge of the Magic Circle. Defining Pervasive Games. Proceedings of DAC 2005 Conference. Available from here (last accessed December 15, 2007).

Murray, J, (1997) Hamlet on the Holodeck: The Future of Narrative in Cyberspace. MIT Press, Cambridge, MA.

Nadolski, R., Hummel, H. Brink, H. van de, Hoefakker, R., Slootmaker, A., Kurvers, H. \& Storm, J. (2007) Emergo: Methodology and Toolkit for Efficient Development of Serious Games in Higher Education. To be published in Electronic Games, simulations and Personalized eLearning.

Prensky, M. (2006) Digital Natives. Learning in the Digital Age 63(4), 8-13.

Quinn, C.N. (2005) Engaging learning. Designing E-Learning Simulation Games. Pfeiffer, John Wiley and Sons, Inc., San Francisco.

Reeves, B. \& Nass, C. (1996) The Media Equation: how People treat Computers, Television, and New Media like real People and Places. Cambridge University Press, Cambridge.

Rieber, L.P. (2005). Multimedia learning in games, simulations, and microworlds. In The Cambridge Handbook of Multimedia Learning (Mayer, R.E. ed.), 549-567. Cambridge University Press, Cambridge, UK.

Rosmalen, P. van, Brouns, F., Tattersall, C., Vogten, H., van Bruggen, J., Sloep, P. \& Koper, R. (2005) Towards an Open Framework for Adaptive, Agent-Supported E-Learning. International Journal of Continuing Engineering Education and Lifelong Learning 15(3-6), 261-275.

Salen, K. \& Zimmerman, E. (2004) Rules of Play, Game Design Fundamentals. MIT Press, Cambridge, MA. 
Serious Game Initiative (2002) Available from here (last accessed December 15, 2007).

Squire, K. (2002) Cultural Framing of Computer/Video Games. Game Studies 2(1). Available from here (last accessed December 15, 2007).

Steinkuehler, C.A. (2004) Learning in Massively Multiplayer Online Games. Proceedings of the 6th international conference on Learning Sciences, 521-528, Santa Monica, CA.

Westera, W. (1999) A Didactic Framework for Audiovisual Design. Journal of Educational Media 24(2), 87-102.

Westera, W., Sloep, P.B. \& Gerrissen, J. (2000). The Design of the Virtual Company; Synergism of Learning and Working in a Networked Environment Innovations in Education and Training International 37 (1), 23-33.

Westera, W., Hommes, M. A., Houtmans, M., \& Kurvers, H. J. (2003). Computer-Supported Training of Psychodiagnostic Skills. Interactive Learning Environments 11(3), 215-231.

Wong, W.K., Chan, T.W., Chou, C.Y., Heh, J.S. \& Tung, S.H. (2003) Reciprocal Tutoring using Cognitive Tools. Journal of Computer Assisted Learning 19, 416-428. 


\section{Appendix}

$<<<$ Table 2 about here $>>>$ 


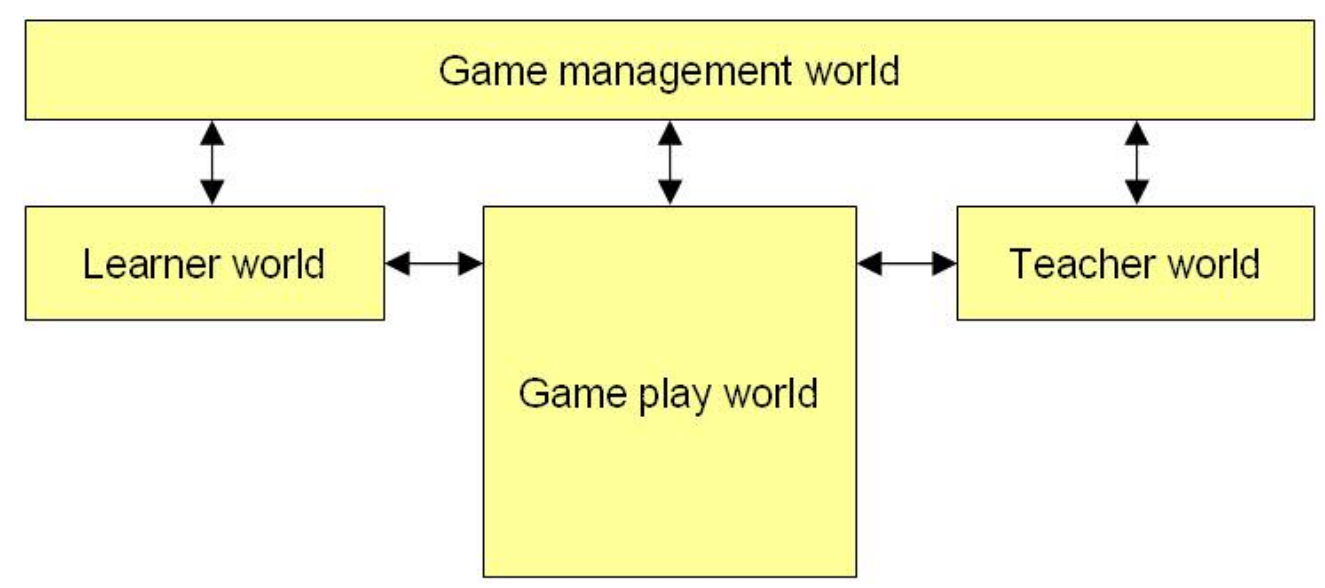

Figure 1. Subsystems of the educational game environment. 


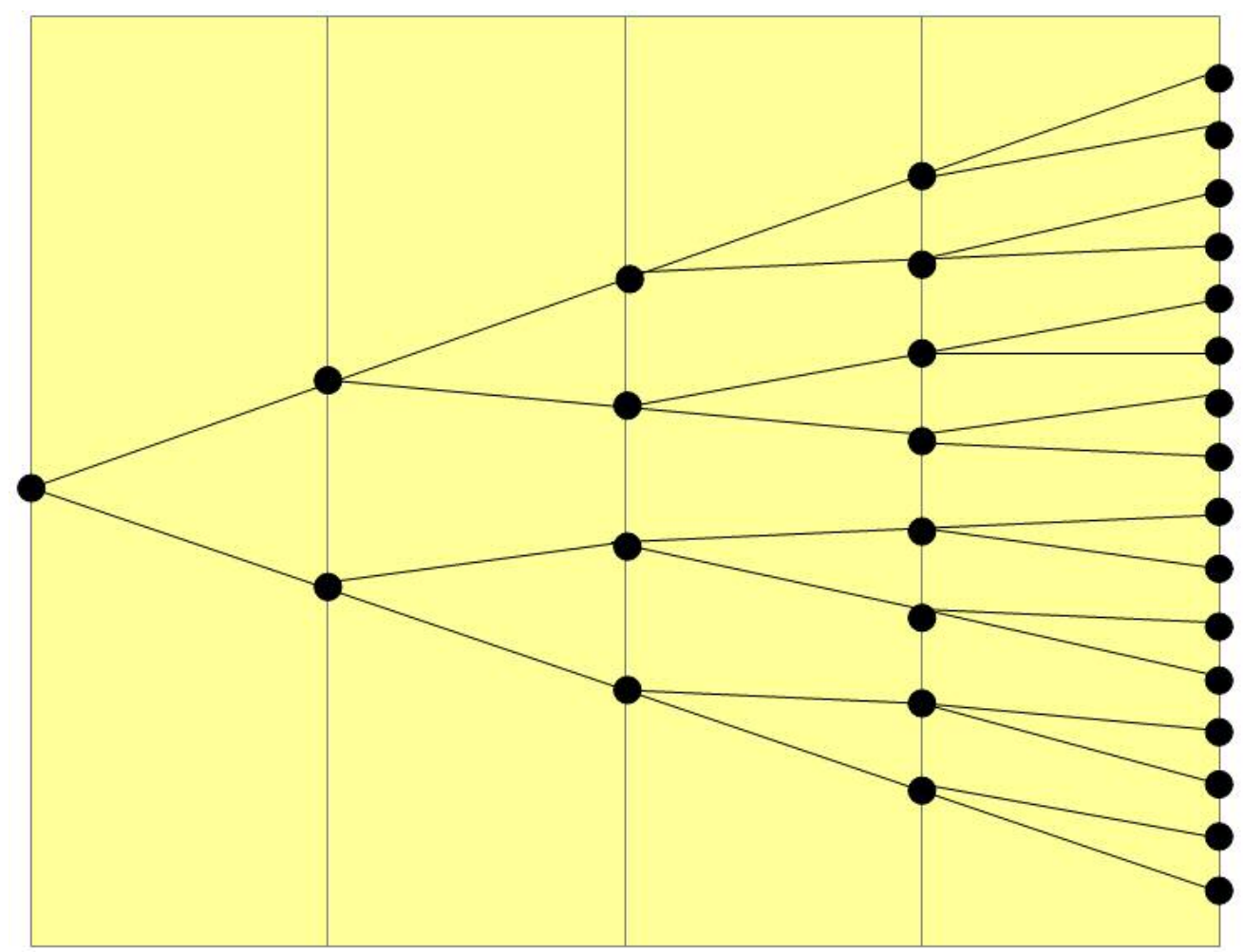

Figure 2. A decision tree as the abstract lay-out of subsequent learner options. 


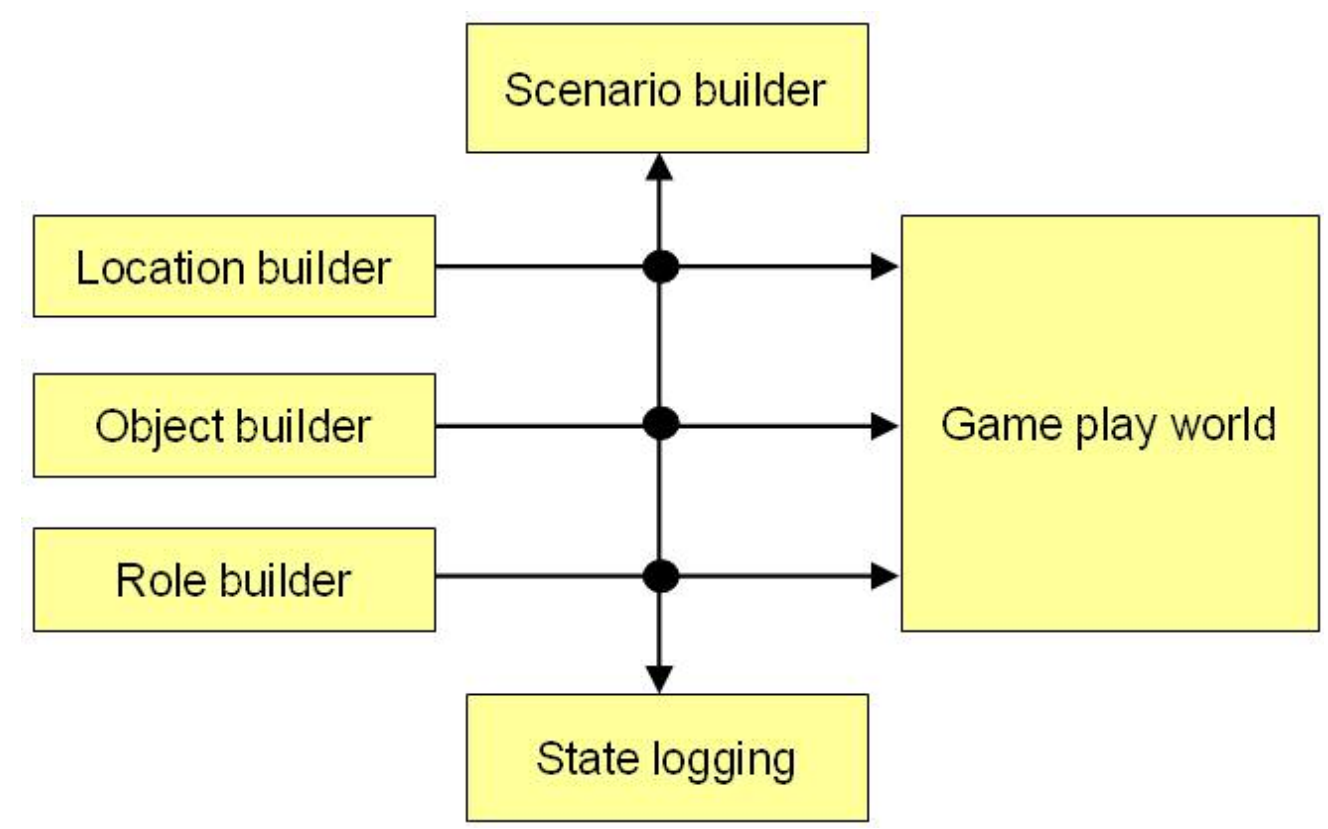

Figure 3. Basic architecture of scenario-based game development 


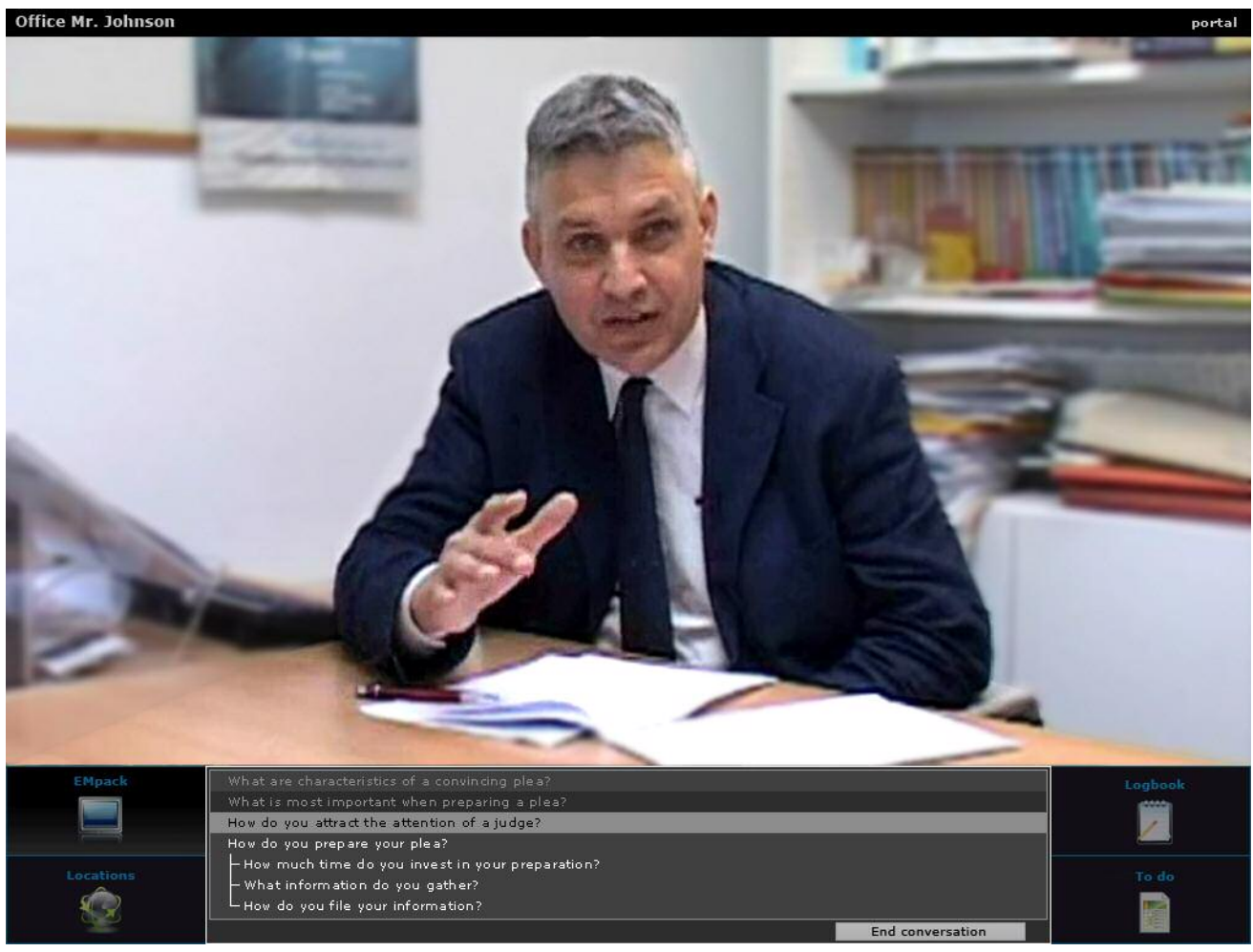

Figure 4. Video interview in one of the games. The learner can consult non-playing characters by selecting questions from the list. $258 \times 194 \mathrm{~mm}(100 \times 100 \mathrm{DPI})$ 


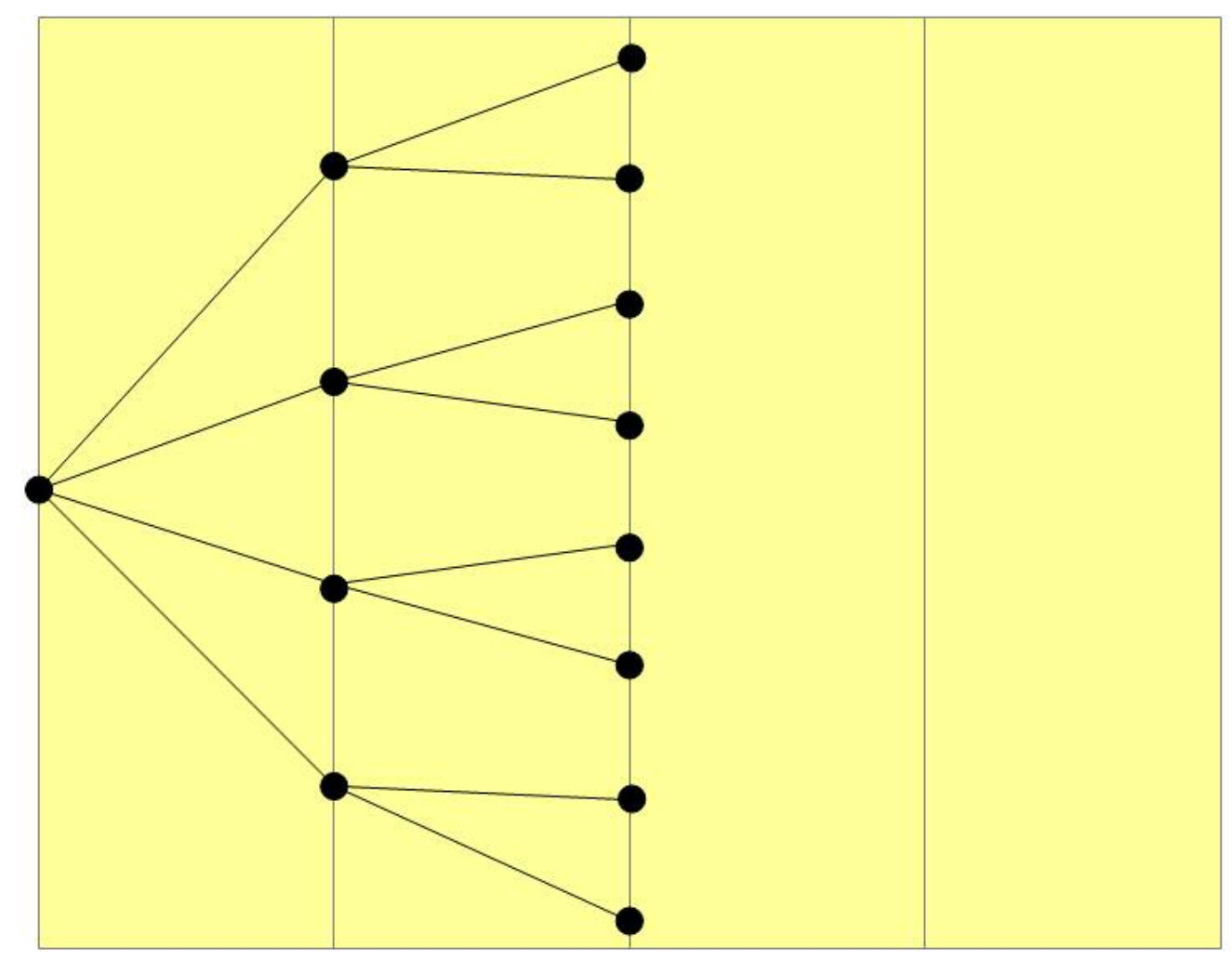

Figure 5. Reducing design complexity by offering option width rather than option depth (cf. Figure 2). 


\begin{tabular}{|l|l|}
\hline Game component & State parameter \\
\hline Location & $\begin{array}{l}\text { Visited/ not visited } \\
\text { Number of visits } \\
\text { Time of visit } \\
\text { Duration of visit }\end{array}$ \\
\hline Activities & $\begin{array}{l}\text { Number of start-up trials } \\
\text { Accessed/not accessed }\end{array}$ \\
\hline Tool contents & $\begin{array}{l}\text { Viewed/ not viewed } \\
\text { Question asked/ not asked (interviews) } \\
\text { Used/ not used }\end{array}$ \\
\hline Learning tasks & $\begin{array}{l}\text { Started/ not started } \\
\text { Completed/ not completed }\end{array}$ \\
\hline Learners products & $\begin{array}{l}\text { Started/ not started } \\
\text { Completed/ not completed }\end{array}$ \\
\hline Non playing characters & Met/ not met \\
\hline Time & $\begin{array}{l}\text { Nett time since game run start } \\
\text { Nett time since user start }\end{array}$ \\
\hline Resources & $\begin{array}{l}\text { Viewed/ not viewed } \\
\text { Interrupted/ not interrupted }\end{array}$ \\
\hline
\end{tabular}

Table 1. General overview of state attributes 


\begin{tabular}{|c|c|}
\hline Actor & $\begin{array}{l}\text { Game object which may represent a non-playing character or a } \\
\text { human game player. }\end{array}$ \\
\hline Event & A state change of any game object \\
\hline Game logic & $\begin{array}{l}\text { The collection of triggers and the underlying rules acting on the game } \\
\text { world and its users }\end{array}$ \\
\hline $\begin{array}{l}\text { Game management } \\
\text { world }\end{array}$ & $\begin{array}{l}\text { Subsystem of the educational game environment where the different } \\
\text { game runs are arranged and co-ordinated }\end{array}$ \\
\hline Game object & $\begin{array}{l}\text { Any component of the world of game play which represents an } \\
\text { artefact, actor or concept. }\end{array}$ \\
\hline Game play & $\begin{array}{l}\text { Context of operation defined by the rules of play and the physical and } \\
\text { temporal boundaries of the game }\end{array}$ \\
\hline Learner world & $\begin{array}{l}\text { Subsystem of the educational game environment which contains the } \\
\text { learner and its specific context }\end{array}$ \\
\hline Location & $\begin{array}{l}\text { Game object which conforms to a spatial metaphor by representing a } \\
\text { particular environment for specific actions }\end{array}$ \\
\hline Location builder & Technical tool for defining game locations \\
\hline Object builder & $\begin{array}{l}\text { A set of different technical tools for specifying game objects and the } \\
\text { associated objects' attributes }\end{array}$ \\
\hline Option space & $\begin{array}{l}\text { The number of alternative actions that learners may choose at a } \\
\text { particular location or point in time }\end{array}$ \\
\hline Role builder & $\begin{array}{l}\text { Technical tool for specifying different player roles, associated with } \\
\text { different tasks and different powers }\end{array}$ \\
\hline Scenario-based game & $\begin{array}{l}\text { Game with some predefined narrative structure for the triggering of } \\
\text { appropriate le arning experiences and activities }\end{array}$ \\
\hline Scenario builder & $\begin{array}{l}\text { Technical tool for constructing the logical conditions that make up } \\
\text { the game play scenario }\end{array}$ \\
\hline Serious game & $\begin{array}{l}\text { Game in which education (in its various forms) is the primary goal, } \\
\text { rather than entertainment (Michael et al., 2006) }\end{array}$ \\
\hline State logging & $\begin{array}{l}\text { Technical tool for the monitoring and registering of the state data of } \\
\text { locations, objects and players }\end{array}$ \\
\hline Subject & $\begin{array}{l}\text { Game object which may represent a non-playing character or a } \\
\text { human game player }\end{array}$ \\
\hline Teacher world & $\begin{array}{l}\text { Subsystem of the educational game environment which contains the } \\
\text { teacher and its specific context }\end{array}$ \\
\hline World of game play & $\begin{array}{l}\text { Subsystem of the educational game environment where learners } \\
\text { interact with game objects, locations and other actors }\end{array}$ \\
\hline
\end{tabular}

Table 2. Glossary of terms 